\title{
Speed Control of Permanent Magnet DC Motor by using Combination of Adaptive Controller and Fuzzy Controller
}

\author{
S. Z. Moussavi \\ Department of Electrical \\ Engineering \\ Islamic Azad University \\ Central Tehran Branch, Iran.
}

\author{
M. Alasvandi \\ Department of Electrical \\ Engineering \\ Islamic Azad University \\ Central Tehran Branch, Iran
}

\author{
Sh. Javadi \\ Department of Electrical \\ Engineering \\ Islamic Azad University \\ Central Tehran Branch, Iran
}

\begin{abstract}
A novel controller based on adaptive controller and fuzzy controller for Permanent Magnet Direct Current motor is proposed in this paper. The proposed controller is compared with adaptive controller and fuzzy controller for PMDC motor. By means of simulation in MATLAB, we concluded that the proposed controller will be achieved the shorter settling time and also lower overshoot and steady state error.
\end{abstract}

\section{General Terms}

Controller, Simulation, MATLAB.

\section{Keywords}

Adaptive Controller, Fuzzy Controller, Permanent Magnet DC Motor.

\section{INTRODUCTION}

In recent years, permanent magnet DC motors are used in variety of application including heater, wiper and air conditioner of car and personal computer. These motors need no excitation current; hence no energy consumption due to field fluxes producing. In addition, PMDC motors have no requirement for winding field therefore size of PMDC motors are smaller than conventional DC motors and cost of PMDC motors are relatively lower.

These motors are done mainly controls through the control of the armature. There are there general method for controlling motors[2]:
1. The classic PID controller.
2. Modern controller (adaptive and improving).
3. Intelligent controller (fuzzy and neural).

In recent years, variety methods of controllers are combined to improve overall performance of plant.

The requirement of high performance control systems for industrial applications has produced great research efforts for the application of modern control theory and, in particular adaptive control. Adaptive control is a rather recent class of control technique, although research in adaptive control has a long and vigorous history. In 1950s, it was motivated by the problem of designing autopilots for aircraft operating at wide range of speeds and altitudes [3].

Fuzzy control has been making rapid progress in recent years. Fuzzy logic control has been widely exploited for nonlinear, high order \& time delay system[4], The effective and efficient control using fuzzy logic has emerged as a tool to deal with uncertain, imprecise or qualitative decision making problems [7].

In this paper a novel strategy based on adaptive controller and fuzzy logic controller is proposed for PMDC motor speed control system to achieve more reasonable performance. The paper is organized as follow: Section 2 discusses model of permanent magnet DC motor. The adaptive controller is explained in section 3. Section 4 presents fuzzy logic control. The proposed strategy explained in section 5 . The simulation results and investigation are given finally in section 6 .

\section{MODEL OF PERMANENT MAGNET DC MOTOR}

The dynamic model for a PMDC motor is derived from both the electrical circuit and mechanical equations of motion. The equations describing the characteristics of a PMDC motor is follow as [1]:

$$
\begin{aligned}
& \frac{d i_{A}(t)}{d t}=-\frac{R_{A}}{L_{A}} i_{A}(t)-\frac{K_{T}}{L_{A}} \omega_{M}(t)+\frac{1}{L_{A}} U_{T}(t) \\
& \frac{d \omega_{M}(t)}{d t}=\frac{K_{T}}{J_{M}} i_{A}(t)-\frac{B_{M}}{J_{M}} \omega_{M}(t)-\frac{1}{J_{M}} T_{L}(t)
\end{aligned}
$$

where $\omega_{M}$ is rotor speed, $i_{A}$ is motor current, $B_{M}$ is viscous friction constant, $J_{M}$ is inertia of rotor, $T_{L}$ is load torque, $R_{A}$ is armature resistance, $\mathrm{L}_{\mathrm{A}}$ is armature inductance, $\mathrm{K}_{\mathrm{T}}$ is back electromotive force (EMF) constant or torque constant and $\mathrm{U}_{\mathrm{T}}$ is applied voltage to motor. In PMDC motor, the electromagnetic torque $\left(\mathrm{T}_{\mathrm{E}}\right)$ and the back $\operatorname{EMF}\left(\mathrm{u}_{\mathrm{b}}\right)$ are proportional to motor current and speed motor, respectively. The back electromotive force $\left(\mathrm{K}_{\mathrm{T}}\right)$ determined by the strength of magnet, reluctance of iron and number of turns of armature winding[1].. An armature controlled PMDC motor as shown in Figure 1, which further used in simulation approach.

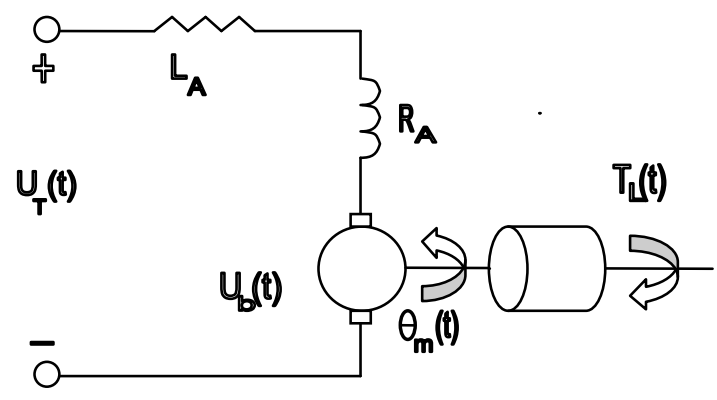

Figure 1: Model of armature controlled de motor [1] 
Relations (1) and (2) could be transformed to state space, the state variables are chosen as follows:

$$
\mathrm{x}_{1}=\mathrm{i}_{\mathrm{A}}, \mathrm{x}_{2}=\omega_{\mathrm{M}}
$$

Matrix form of state space equation as follows:

$$
\begin{aligned}
& \frac{d}{d t}\left[\begin{array}{c}
i_{A} \\
\omega_{M}
\end{array}\right]=\left[\begin{array}{cc}
\frac{-R_{A}}{\mathrm{~L}_{A}} & \frac{-K_{T}}{\mathrm{~L}_{A}} \\
\frac{\mathrm{K}_{T}}{\mathrm{~J}_{M}} & \frac{-B_{M}}{\mathrm{~J}_{M}}
\end{array}\right]\left[\begin{array}{c}
\mathrm{i}_{\mathrm{A}} \\
\omega_{\mathrm{M}}
\end{array}\right]+\left[\begin{array}{cc}
\frac{1}{\mathrm{~L}_{\mathrm{A}}} & 0 \\
0 & \frac{-1}{\mathrm{~J}_{\mathrm{M}}}
\end{array}\right]\left[\begin{array}{c}
\mathrm{U}_{\mathrm{T}} \\
\mathrm{T}_{\mathrm{L}}
\end{array}\right] \\
& \mathrm{y}=\left[\begin{array}{ll}
0 & 1
\end{array}\right]\left[\begin{array}{c}
\mathrm{i}_{\mathrm{A}} \\
\omega_{\mathrm{M}}
\end{array}\right]+\left[\begin{array}{ll}
0 & 0
\end{array}\right]\left[\begin{array}{c}
\mathrm{U}_{\mathrm{T}} \\
\mathrm{T}_{\mathrm{L}}
\end{array}\right]
\end{aligned}
$$

The transfer function model of the PMDC motor is obtained from below equation:

$$
\frac{\mathrm{K}_{\mathrm{T}}}{\mathrm{L}_{\mathrm{A}} \mathrm{J}_{\mathrm{M}} \mathrm{s}^{2}+\left(\mathrm{R}_{\mathrm{A}} \mathrm{J}_{\mathrm{M}}+\mathrm{L}_{\mathrm{A}} \mathrm{B}_{\mathrm{M}}\right) \mathrm{s}+\left(\mathrm{R}_{\mathrm{A}} \mathrm{B}_{\mathrm{M}}+\mathrm{K}_{\mathrm{T}}^{2}\right)}
$$

\section{ADAPTIVE CONTROLLER}

Model reference adaptive control (MRAC) is the control method for uncertain and undesirable system. This control method uses stable and optimum reference model for increasing performance of controller. By using this method, plant will have desired response.

A stable reference model (RM) which decides the degree of stability (DS) of the complete scheme is selected such that, its steady state speed is the same as the desired speed of the plant[6]. Different rules are used in MRAC such as Lyapunov rule, MIT rule. In this paper, we use MIT rule for MRAC.

This technique of adaptive control falls under the category of Non-dual adaptive control. A reference model describes the system's performance. The adaptive controller is then designed to force the system (or plant) to behave like the reference model. Model output is compared to the actual output, and the difference is used to adjust feedback controller parameters. MRAC has two loops: an inner loop (or regulator loop) that is an ordinary control loop consisting of the plant and the regulator, and an outer (or adaptation) loop that adjusts the parameters of the regulator in such a way as to drive the error between the model output and plant output to zero, as shown in Figure $2[3]$.

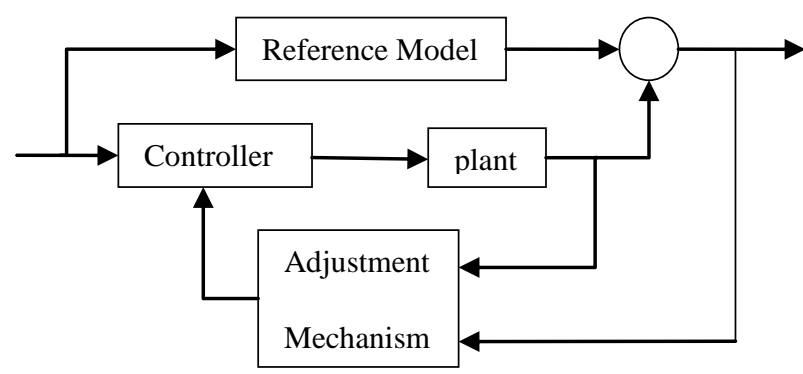

Figure 2: Model Reference Adaptive Controller [3]

Reference Model: This part of controller specifies the desired model. It should reflect the performance specifications in control tasks[3]. In fact, the adaptive controller forced actual system to behave like reference model. Proper choice of reference model is very important, to achieve optimal response.
Controller: It is usually parameterized by a number of adjustable parameters. The control law is linear in terms of the adjustable parameters (linear parameterization). Adaptive controller design normally requires linear parameterization in order to obtain adaptation mechanism with guaranteed stability and tracking convergence. The values of these control parameters are mainly dependent on adaptation gain which in turn changes the control algorithm of adaptation mechanism[3].

Adaptation Mechanism: It is used to adjust the parameters in the control law. Adaptation law searches for the parameters such that the response of the plant which should be same as the reference model. It is designed to guarantee the stability of the control system as well as conversance of tracking error to zero. [3].

This rule was developed in Massachusetts Institute of Technology and is used to apply the MRAC approach to any practical system. In this rule the cost function or loss function is defined as[3]:

$$
\mathrm{F}(\theta)=\frac{\mathrm{e}^{2}}{2}
$$

Where, e is the output error and is the difference of the output of the reference model and the actual model, while $\theta$ is the adjustable parameter known as the control parameter. In this rule the parameter $\theta$ is adjusted in such a way so that the loss function is minimized. Therefore, it is reasonable to change the parameter in the direction of the negative gradient of $\mathrm{F}$, that is[3]:

$$
\begin{aligned}
& \frac{\mathrm{d} \theta}{\mathrm{dt}}=-\frac{\gamma \partial \mathrm{F}}{\partial \theta} \\
& =-\gamma \mathrm{e} \frac{\partial \mathrm{e}}{\partial \theta}
\end{aligned}
$$

The partial derivative term $\partial \mathrm{e} / \partial \theta$, is called the sensitivity derivative of the system. This shows how the error is dependent on the adjustable parameter, $\theta$. There are many alternatives to choose the loss function F. For example, it can also be taken as mode of error. Similarly $\mathrm{d} \theta / \mathrm{dt}$ can also have different relations for different applications[3].

Sign-sign algorithm:

$$
\frac{\mathrm{d} \theta}{\mathrm{dt}}=-\gamma \operatorname{sign}\left(\frac{\partial \mathrm{e}}{\partial \theta}\right) \operatorname{sign} \mathrm{e}
$$

Or it may be chosen as :

$$
\frac{\mathrm{d} \theta}{\mathrm{dt}}=-\gamma\left(\frac{\partial \mathrm{e}}{\partial \theta}\right) \operatorname{sign} \mathrm{e}
$$

Where sign $\mathrm{e}=1$ for $\mathrm{e}>0$

$$
\begin{aligned}
& =0 \text { for } \mathrm{e}=0 \\
& =-1 \text { for } \mathrm{e}<0
\end{aligned}
$$

In some industrial applications it is found that the choice of adaptation gain is critical and its value depends on the signal levels. So MIT rule has to be modified as follows[3]:

$$
\frac{\mathrm{d} \theta}{\mathrm{dt}}=-\gamma \zeta \mathrm{e}
$$

Where $\zeta=\frac{\partial \mathrm{e}}{\partial \theta}$

$$
\text { Also } \frac{\mathrm{d} \theta}{\mathrm{dt}}=-\gamma \zeta \frac{\mathrm{e}}{\beta+\zeta^{\mathrm{T}} \zeta}
$$


Where $\beta>0$ is introduced to avoid the zero division when $\zeta^{\mathrm{T}} \zeta$ is small. Using the MIT rule defined by equations (5), (6) and (7) for developing the control law [3].

\section{FUZZY LOGIC CONTROLLER}

In recent years, fuzzy control used in wide variety of application such as image processing, wind turbines, boilers, and motors.

The general fuzzy logic controller consists of four parts as illustrated in Figure 3. They are fuzzification, fuzzy rule-base, fuzzy inference engine and defuzzification [5].

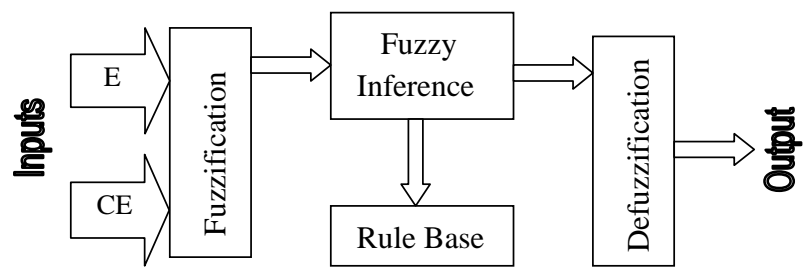

Figure 3: Structure of fuzzy controller [5]

Heuristic and expert knowledge are often expressed linguistically in the form of IF-THEN rules[9]. The control rules that relate the fuzzy output to the fuzzy inputs are derived from general knowledge of the system behavior, also the perception and experience. However, some of the control rules are developed using "trial and error" method[7].

Different part of the fuzzy controller is described as follows:

1. Fuzzification: this part converts crisp value of input of fuzzy controller to fuzzy value.

2. Rule base: A collection of the expert control rules (knowledge) needed to achieve the control goal[8]. These rules can be extracted from common sense, intuitive knowledge, survey results, general principles and laws, and other means that reflect real-world situations[9].

3. Fuzzy inference: This process will perform fuzzy logic operations and result the control action according to the fuzzy input. [8].

4. Defuzzification: The reverse process of fuzzification is called defuzzification[7]. this part converts fuzzy value of the output of fuzzy inference to crisp value.

In this paper, fuzzy logic controller is used minimum number of membership function therefore this controller is very easy for implementation. This fuzzy controller has 4 rule for describing all available condition whereas other similar controller uses more numbers of rules.

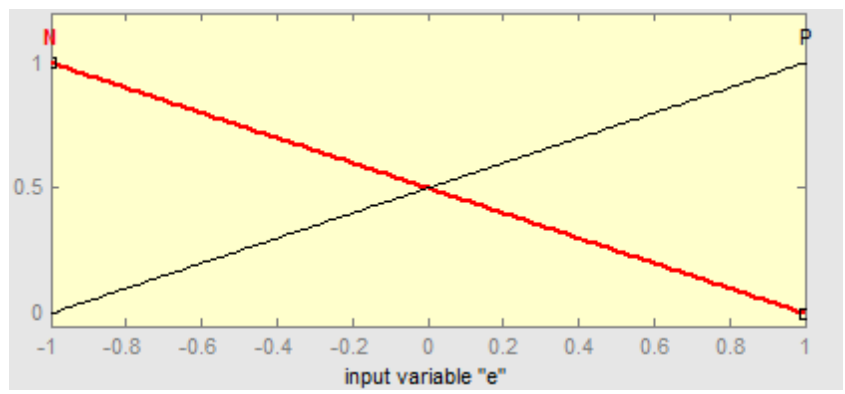

Figure 4: Membership functions for inputs e and $\dot{e}$

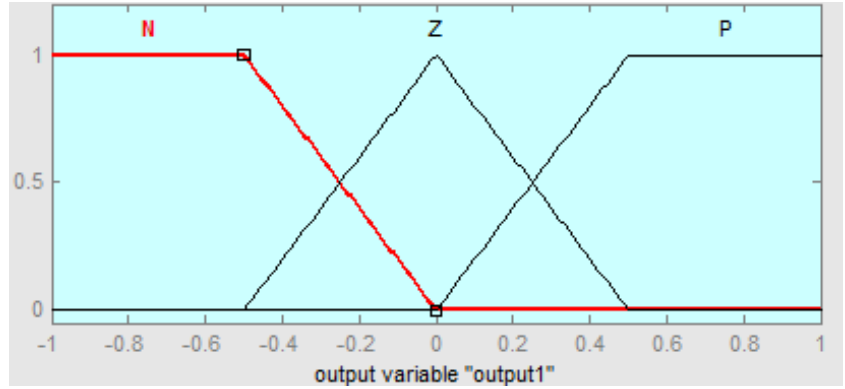

Figure 5: Membership functions for output

Four rules were derived for the fuzzy logic controller (Table1). These four rules are sufficient to cover all possible situations [4].

Table 1. Rule of fuzzy controller [4]

\begin{tabular}{|c|c|c|}
\hline e & $\mathrm{N}$ & $\mathrm{P}$ \\
\hline $\mathrm{N}$ & $\mathrm{N}$ & $\mathrm{Z}$ \\
\hline $\mathrm{P}$ & $\mathrm{Z}$ & $\mathrm{P}$ \\
\hline
\end{tabular}

\section{PROPOSED CONTROLLER}

In this work, adaptive controller and fuzzy controller is applied to achieve reasonable rise time, settling time, overshoot and steady state error. The proposed strategy minimized error of reference model and response of PMDC motor by combination model reference adaptive control and fuzzy control. In proposed method, the fuzzy controller is located in error path of MRAC schematic in order to modify error (error of reference model and actual model).

We should use proper system for reference model therefore second order critically damped system selected as the reference model. The transfer function is written as:

$$
\frac{Y_{m}}{U}=\frac{400}{s^{2}+40 s+400}
$$

Proper reference model and fuzzy controller can be improved performance of PMDC motor.

In this paper the model of proposed controller is simulated in Simulink. The simulation model of fuzzy adaptive controller is shown in Figure 6.

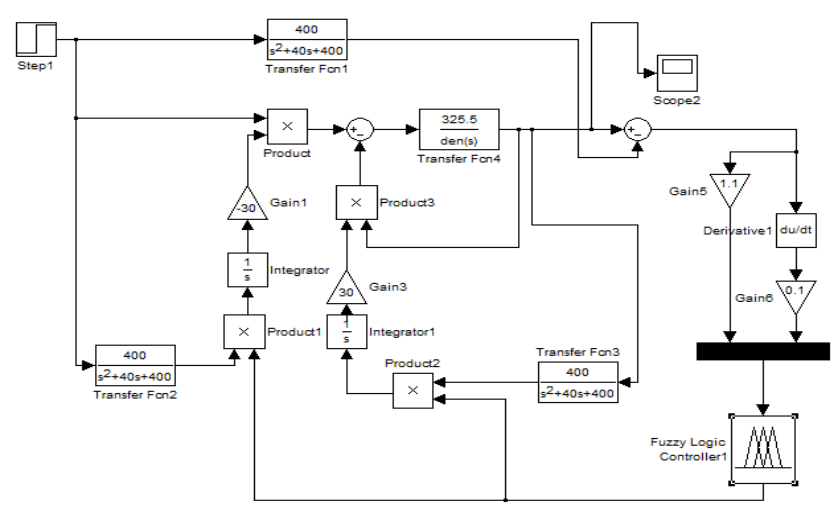

Figure 6: Simulation model for proposed strategy 


\section{SIMULATION DISCUSSION}

RESULTS

AND

Parameter of permanent magnet DC motor as follows:

$\mathrm{R}_{\mathrm{A}}=7.72(\Omega), \mathrm{L}_{\mathrm{A}}=0.16273(\mathrm{H}), \mathrm{K}_{\mathrm{T}}=1.25(\mathrm{Nm}), \mathrm{B}_{\mathrm{M}}=0.003$ (N.m.s/r) and $\mathrm{J}_{\mathrm{M}}=0.0236\left(\mathrm{~kg} \cdot \mathrm{m}^{2}\right)[1]$.

The transfer function of PMDC motor is written as:

$$
\frac{Y}{U}=\frac{325.5}{s^{2}+47.57 s+412.9}
$$

The results of simulation are given in Figure 7-9. Error curve is shown in Figure 7. The step response of PMDC motor with adaptive controller and proposed controller are shown in Figure 8 . The step response of PMDC motor with proposed controller and fuzzy controller are shown in Figure 9.

Figure 7 shows the error of reference model and actual model (PMDC motor). Error of reference model and actual model (PMDC motor) by using fuzzy controller in proposed controller is modified. Error of reference model and actual model by using proposed controller at $\mathrm{t}=0.3633 \mathrm{~s}$ and by using adaptive controller at $\mathrm{t}=3.5528 \mathrm{~s}$ are almost near zero (accuracy \%2). By using proposed controller the error of reference model and actual model is zero in minimum time, therefore this strategy can be decreased error and this strategy is suitable for increasing performance of controller.

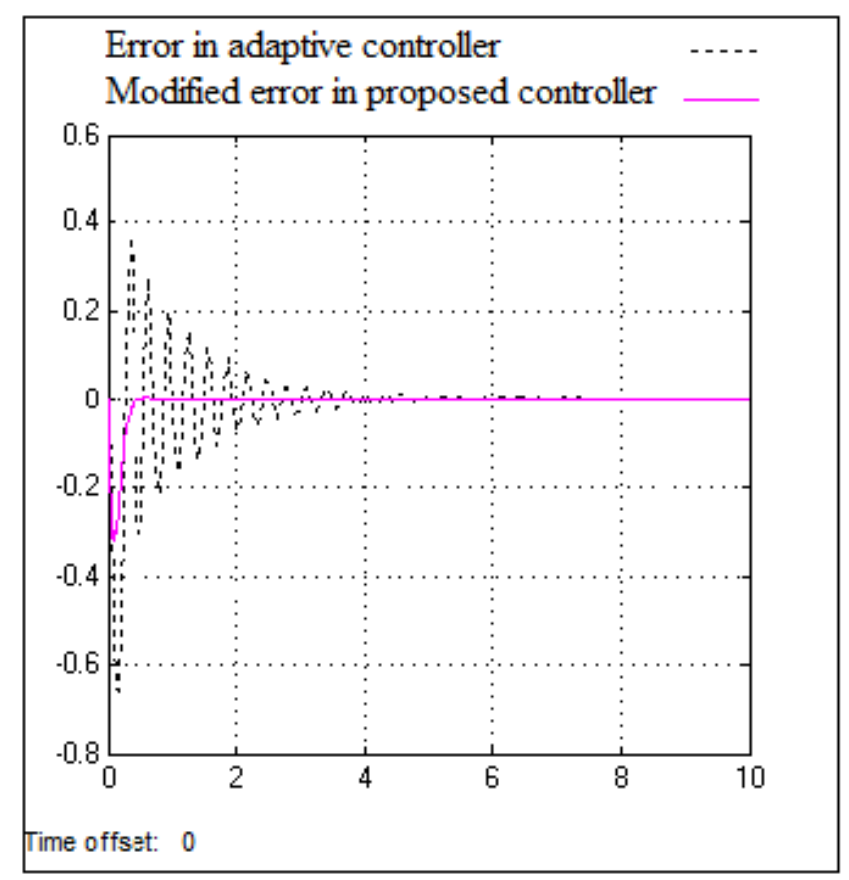

Figure 7: Error of reference model and actual model

Figures 8 shows step response of system by using adaptive controller and proposed controller. Overshoot and settling time of proposed controller are very smaller than adaptive controller. Therefore proposed controller have proper performance.

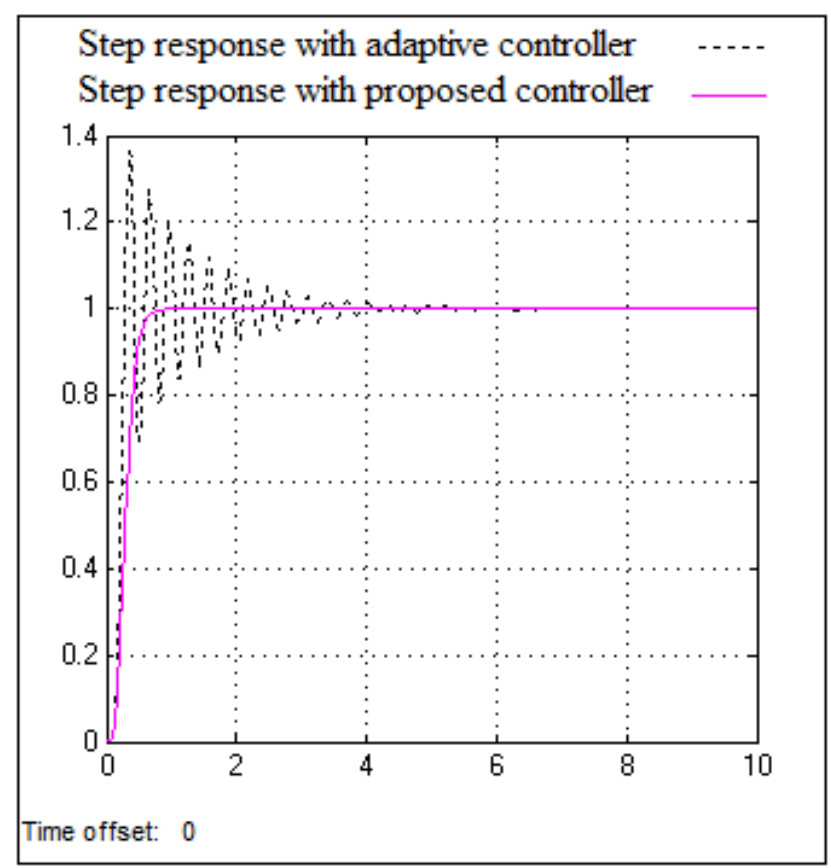

Figure 8: Step response of system by using adaptive controller and proposed controller

Figure 9 shows step response of system by fuzzy controller and proposed controller. Simulation shows steady state error of proposed controller is very smaller than fuzzy controller. Fuzzy controller have undesirable steady state error, whereas proposed controller have zero steady state error.

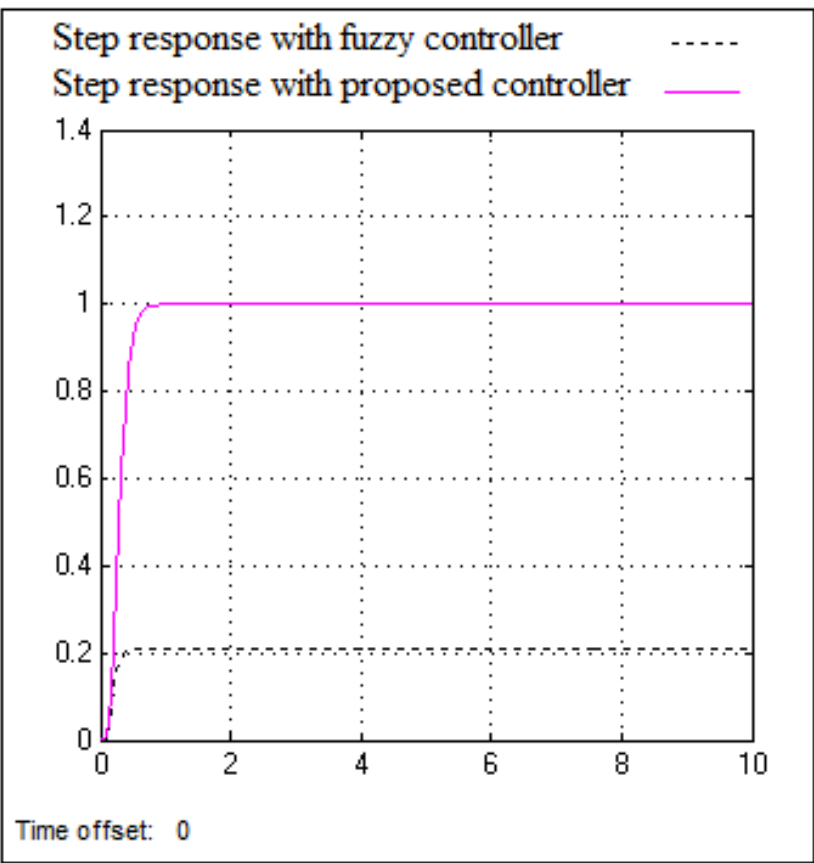

Figure 9: Step response of system by using fuzzy controller and proposed controller 
The rise time, settling time, steady state error and overshoot are shown in table 2 (accuracy $0.01 \%$ ).

Table 2. Performance criteria of step response

\begin{tabular}{|c|c|c|c|c|}
\hline Method & $\begin{array}{c}\text { Rise } \\
\text { Time (s) }\end{array}$ & $\begin{array}{c}\text { Settling } \\
\text { Time (s) }\end{array}$ & $\begin{array}{c}\text { steady } \\
\text { state } \\
\text { error }\end{array}$ & $\begin{array}{c}\text { overshoot } \\
(\mathbf{\%})\end{array}$ \\
\hline $\begin{array}{c}\text { Adaptive } \\
\text { Control }\end{array}$ & 0.1204 & 3.5528 & 0 & 36.46 \\
\hline $\begin{array}{c}\text { Fuzzy } \\
\text { Controller }\end{array}$ & 0.1967 & 0.3667 & 0.7907 & 0 \\
\hline $\begin{array}{c}\text { Proposed } \\
\text { Controller }\end{array}$ & 0.3192 & 0.6270 & 0 & 0 \\
\hline
\end{tabular}

\section{CONCLUSION}

The behavioral charachteristics of the designed controller resulted from technique simulation summerize in table 2. From which the rise time is $0.3192 \mathrm{~s}$ and settling time is $0.6270 \mathrm{~s}$ and steady satate error is 0 and overshoot is 0 . Comparing our proposed controller to adaptive controller, we observe that the percent maximum overshoot and settling time are considerably improved. On the other hand, comparing proposed controller to fuzzy controller, we observe that the steady state error improved in proposed controller. Also in the proposed controller rise time is longer but even so reasonable. According to what was mentioned, proposed controller improves the performance of PMDC motor by decreasing overshoot and settling time and steady state error. In addition the fuzzy segment of proposed controller is using smaller number of rule sets to improve performance of PMDC motor therefore implementation this fuzzy segment is readily. Therefore proposed controller strategy can be considered enough good for PMDC motor.

\section{ACKNOWLEDGMENTS}

The Authors thank ISLAMIC AZAD University, Central Tehran Branch as this work is the result of master thesis in electrical engineering (MSc Eng.) with titled "Improvement Performance of Permanent Magnet Motor by Using Fuzzy Controller" which is on focus at the Faculty of Engineering.

\section{REFERENCES}

[1] Ghazanfar Shahgholian, Pegah Shafaghi, " State space modeling and eigenvalue analysis of the permanent magnet DC motor drive system", 2nd International Conference on Electronic Computer Technology, 2010.

[2] Jasmin Velagic, Amar Galijasevic," Design of fuzzy logic control of permanent magnet DC motor under real constraints and disturbances", IEEE International Symposium on Intelligent Control, 2009.

[3] Pankaj Swarnkar, Shailendra Jain, R. K. Nema, "Effect of adaptation gain in model reference adaptive controlled second order system", Engineering, Technology \& Applied Science Research, 2011.

[4] S.R.Vaishnav, Z.J.Khan, "Design and performance of PID and fuzzy logic controller with smaller rule set for higher order system", World Congress on Engineering and Computer Science, 2007.

[5] R. Shanmugasundram, K. Muhammed Zakariah, N. Yadaiah, "Digital implementation of fuzzy logic controller for wide range speed control of brushless DC motor", IEEE International Conference on Vehicular Electronics and Safety, 2009.

[6] A. Suresh kumar, M. Subba Rao, Y.S.Kishore Babu, "Model reference linear adaptive control of DC motor Using Fuzzy Controller", IEEE Region 10 Conference, 2008 .

[7] M. Muruganandam, M. Madheswaran, "Modeling and simulation of modified fuzzy logic controller for various types of DC motor drives", International conference on control, automation, communication, and energy conservation, 2009.

[8] Tan Chee Siong, Baharuddin Ismail, Mohd Fayzul Mohammed, Mohd Faridun Naim Tajuddin, Siti RafidahAbd. Rahim, Zainuddin Mat Isa," Study of fuzzy and PI controller for permanent magnet brushless DC motor drive",4th International Power Engineering and Optimization Conf, 2010.

[9] Shahram Javadi, "Spatial load forecasting using fuzzy logic", WSEAS, Rio de Janeiro, Brazil, 2005. 